\title{
Evolution of the Complex Partnerships between Banks and B2B e-Trading Platforms: A Theoretical Interpretation from the Chinese Market
}

\author{
Jinzhao Shi $\mathbb{D}^{1,2}$ Ju'e Guo $\mathbb{D}^{3}{ }^{3}$ Qiang Du $\mathbb{D}^{1,2}$ Libiao Bai $\mathbb{D}^{1,2}$ Yi Li $\mathbb{D}^{3},{ }^{3}$ Wenjun Yan, \\ and Kin Keung Lai $\mathbb{B}^{4}$ \\ ${ }^{1}$ School of Economics and Management, Chang'an University, Middle-section of Nan'er Huan Road, Xi'an 710064, \\ Shaanxi, China \\ ${ }^{2}$ Research Center for Green Engineering and Sustainable Development, Chang'an University, \\ Middle-section of Nan'er Huan Road, Xi'an 710064, China \\ ${ }^{3}$ School of Management, Xi'an Jiaotong University, No. 28 Xianning West Road, Xi'an 710049, Shaanxi, China \\ ${ }^{4}$ College of Economics, Shenzhen University, Nanhai Ave 3688, Shenzhen 518060, China \\ Correspondence should be addressed to Kin Keung Lai; mskklai@outlook.com
}

Received 2 August 2019; Revised 2 January 2020; Accepted 6 January 2020; Published 15 May 2020

Academic Editor: Ning Cai

Copyright (c) 2020 Jinzhao Shi et al. This is an open access article distributed under the Creative Commons Attribution License, which permits unrestricted use, distribution, and reproduction in any medium, provided the original work is properly cited.

\begin{abstract}
Based on the principal-agent theory, we give a theoretical interpretation on evolution of the complex partnerships between the online SCF (supply chain finance) providers in China. First, we describe the principal-agent relationships and analyze the optimal profit-sharing contracts between the banks and the B2B platforms. Then, from a dual perspective of leadership transfer and absolute benefit change, we explain the behavioral choices of the banks in the cooperation. Results show that, at the initial stage of growth of the platforms' abilities to rate online borrowers, the leadership and the absolute benefit of the banks will suffer a "double decline," which explains why the leading banks in China "divorced" the B2B platforms during 2011 to 2013. However, as the platforms' rating abilities grow to "maturity," the absolute benefit of the banks will finally exceed its original level, and then the rational banks would cooperate with the platforms again even at the expense of losing a portion of their leadership, which answers why the banks in China have come back to "remarry" the B2B platforms since 2014.
\end{abstract}

\section{Introduction}

The supply chain finance (SCF), a set of short-term financing solutions focused on accounts payable, accounts receivable, and inventory in supply chains, has received substantial attention since 2008 when global financial crisis broke out and the credit crunch spread in the traditional credit channels $[1,2]$. With the growing popularity of e-commerce and development of big data technology, the online supply chain finance (OL-SCF) has developed rapidly and is extensively applied in the world's major economies. The B2Bbased OL-SCF which aims at providing short-term working capital for online-trading SMEs is one of the most popular modes $[3,4]$. In such a mode, banks can evaluate the creditworthiness of online SMEs jointly with third-party B2B platforms on which a large amount of electronic credit information of SMEs is generated, e.g., transaction records and customer reviews, which can serve as supplementary information of SMEs' financial creditworthiness $[4,5]$. Since the financial credit data of SMEs are usually incomplete especially in developing countries, the B2B-based OL-SCF can effectively alleviate the information asymmetry problem faced by banks in rating SMEs, by taking the electronic credit data into account [3]. Thus, banks and B2B platforms usually together serve as the service providers in such a business. However, the cooperation between the two parties seems to be not so smooth. In the following, we give a story in the Chinese market. 
In China, the B2B-based OL-SCF was started in 2007 when China Construction Bank (CCB), Industrial and Commercial Bank of China (ICBC), and Alibaba (a B2B platform in China, http://www.alibaba.com) jointly launched the products/services related to online guarantee loans and online supplier financing [6]. Today, the B2B-based OL-SCF has a variety of patterns, e.g., online purchase/production order financing, online warehouse receipt financing, and online factoring. Apart from Alibaba, almost all leading B2B platforms in China, e.g., JYD (http://www.315.com.cn) and Dun Huang (http://seller. dhgate.com), have launched such financial services in cooperation with banks. As already mentioned, cooperation between banks and B2B platforms is not going well. Taking Alibaba as an example, its cooperation with the banks can be divided into three stages: "marriage," "divorce," and "remarriage."

1.1. Stage 1: Marriage (2007-2010). In this stage, in order to enrich the variety of services available to online SMEs, Alibaba successively cooperated with CCB and ICBC to launch a series of online financing products. In the cooperation, Alibaba just served as a bridge between the banks and online SMEs and provided the banks with free electronic credit data which constituted the main basis for credit evaluation of SMEs. As was expected, the banks alone earned the entire interest income and bored all risks of loan default.

1.2. Stage 2: Divorce (2011-2013). As the ability for collecting and analyzing the electronic credit data generated on the platform grew, Alibaba considered termination of the "free lunch" provided to the banks and sought to grab a slice of interest income in the cooperation. Its request was rejected by the banks, after which the two parties "divorced." On the one hand, banks started to build their self-operated B2B platforms to reduce reliance on Alibaba and other leading platforms. For example, in January 2012, Bank of Communications (http://www.bankcomm.com) set up its own platform called "Jiao Bo Hui (http://e.bankcomm.com);" in July of the same year, CCB opened a platform named "Shan Rong Shang Wu (http://mall.ccb.com)." After that, the Agricultural Bank of China (ABC), ICBC, etc., also launched their self-operated platforms. On the other hand, Alibaba obtained a license for dispensing petty loans from the Chinese government and began to develop its online financing business independently.

1.3. Stage 3: Remarriage (2014). In July 2014, Alibaba again teamed up with CCB and six other banks to provide an advanced online financing service. In the new cooperation, Alibaba began to lead the credit rating and other key processes of loan risk control through a more mature technology of big data. The two parties signed a profit-sharing contract. At this point, Alibaba finally got a part of the interest income from the cooperation.

Why did the banks "divorce" Alibaba during 2011 to 2013? Why did they come back to "remarry" Alibaba in
2014? Using the principal-agent theory, from a dual perspective of leadership transfer and absolute benefit change, this paper is the first to reveal the impacts of B2B platforms' rating ability driven by technical progress in the big data era on evolution of the partnerships between banks and B2B platforms in the OL-SCF business and theoretically explain the practice in the Chinese market, i.e., the complex "marriage-divorce-remarriage" process between the two parties. Since this study is novel, the research findings can provide a reference for the development of OL-SCF services in other markets around the world.

The remainder of the paper is organized as follows. Section 2 presents the literature review. Section 3 elaborates the principal-agent relationships between the bank and the B2B platform. Section 4 examines the optimal profit-sharing contracts between the two parties. Section 5 analyzes how improvement of the platform's rating abilities affects the contract parameters and reveals the transfer of leadership between the two parties in the big data era. Section 6 studies the change of the bank's absolute benefit as the platform's rating ability increases and further explains the complex evolution of partnership between the two parties in the Chinese market. Section 7 gives numerical examples, and Section 8 concludes the study.

\section{Literature Review}

2.1. Research on Supply Chain Finance (SCF). Unlike traditional fixed asset mortgage loans, SCF is a short-term trade financing method designed to optimize the flow of funds in the supply chain and help SMEs obtain working capital for daily operations [7-9]. It has developed rapidly in major economies around the world, e.g., European Union [10], America [2], and China [11, 12]. Existing research on SCF mainly involves its definition $[1,8,13]$, mode $[2,7,14]$, and role $[1,8]$. Other extended research also include companies' adoption of SCF $[15,16]$, as well as integrated financing and operating decisions of companies under the SCF framework $[17,18]$.

Pfohl and Gomm define SCF as the intercompany optimization of financing and the integration of financing processes with customers, suppliers, and service providers [8]; More and Basu view SCF as managing, planning, and controlling all transactional activities and processes related to the flow of cash among supply chain stakeholders in order to improve their working capital flows [13]. For other definitions, see the review work of Gelsomino et al. [1]. SCF includes a variety of practical models, e.g., purchase/production order financing [2], factoring or reverse factoring [14], and inventory-stock financing or goods-in-transit financing [7].

Taking the "purchase order financing" addressed in this study as an example, it helps buyers with limited funds to complete their procurements, enables the sellers to increase the stickiness of downstream buyers through guarantee schemes, and helps banks develop new business models. Therefore, SCF is generally considered to be an all-win mode, which helps to increase the value of all participating companies, e.g., the customers, suppliers, and the service 
providers $[1,8]$. It is such that obvious benefits and advantages have promoted the widespread use of SCF.

2.2. Research on Online Supply Chain Finance (OL-SCF). The concept of "Internet Finance" has developed rapidly in recent years [19]. It is viewed as a powerful weapon to reduce transaction costs and alleviate information asymmetry in financial activities $[4,20]$. Due to its imperfect credit system and low usage of trade credit [21], China has been leading the development of internet finance since 2010 [19]. As suggested by Xie et al. [5], internet finance facilitates integration of financial and nonfinancial factors, which promotes the growth of cross-sector financing products. Among them, the B2B-based OL-SCF is a representative, in which banks and the third-party B2B platforms jointly offer financing services for online-trading SMEs [3].

Credit management of the B2B-based OL-SCF is significantly different from that of the traditional offline SCF modes since a large amount of electronic credit data and information can be generated and collected through the B2B platforms [4], which can be used for evaluating creditworthiness of online borrowers [5]. Therefore, electronic credit is combined into the credit rating process of the OLSCF, acting as a reliable complement to creditworthiness of online SMEs $[3,22]$. The newly added rating indicators may include online exchange history (e.g., registration time), activity level (e.g., trading frequency and transaction amount), interaction intensity with partners (e.g., locations in the trading networks and supply chain stickiness), and customer satisfaction (e.g., online review) [3, 22-24]. Since such information is generally privately possessed by $\mathrm{B} 2 \mathrm{~B}$ platforms, it is a common practice that banks and $\mathrm{B} 2 \mathrm{~B}$ platforms work together as service providers in the OL-SCF business. In China, such services typically include online financing products, e.g., E-Dantong and Ali Finance, released by China Construction Bank and Alibaba, JYD, and other B2B platforms $[3,25]$.

In addition, many scholars highlight the decisive role of information technology in the OL-SCF business. Kshetri [26] points out that big data play an important role in expanding microenterprises' access to financial services in China. Since the majority of the online credit information is unstructured, advanced data mining and information processing technologies are the basis of online credit risk management [23]. Lin et al. [19], Xie et al. [5], and Yaqoob et al. [27] describe the role of big data technology in improving efficiency of risk management in internet-based finance. Other related technologies used in internet finance mainly include machine learning, social network analysis, search engine, cloud computing, and text mining $[5,28,29]$. In practice, some leading online financial service providers have applied such technologies to rating online borrowers and monitoring loans, including commercial banks [5], e-commerce companies [15], and private credit service providers [30].

2.3. Research Gaps and Inspirations. Because of the novelty of SCF, especially the OL-SCF [2], some aspects of this subject are still unexplored in academia [9]. First, the existing literature on SCF and OL-SCF is mainly qualitative discussions and lacks quantitative studies. Second, the research on OL-SCF, especially the B2B-based OL-SCF, is quite inadequate, far behind the industry practice.

Few studies have focused on contract design and evolution of the partnership between the OL-SCF service providers. Shi et al. [31] study the incentive contracts between banks and B2B platforms in the OL-SCF service and present strategies to deal with two kinds of moral hazards, i.e., hidden action (low-level effort in the process of rating the borrowers) and hidden information (recommending low-credit borrowers). They reveal the evolvement law of leadership between banks and B2B platforms in the context of "data-pledge-based" financing age. However, from a dual perspective of leadership transfer and absolute benefit change, this paper reveals the impacts of B2B platforms' rating ability driven by technical progress in the big data era on the evolution of partnerships between banks and B2B platforms in the OL-SCF business and theoretically explains the practice in the Chinese market, i.e., the complex "marriage-divorce-remarriage" process between the two parties. The new findings can provide references for other markets around the world to develop OL-SCF services.

\section{Principal-Agent Relationships between Banks and B2B Platforms}

In this section, we analyze the principal-agent relationships and the hidden moral hazard problems that exist between banks and B2B platforms in the OL-SCF business, which are the basis for investigating the optimal profit-sharing contracts between the two parties. For convenience, we consider a single bank and a single B2B platform.

As aforementioned, the B2B-based OL-SCF has a variety of operating modes. We address one of its main modes, i.e., the online purchase order financing (OPOF) mode. Figure 1 shows a simplified flowchart of the OPOF mode. First, the retailer and its supplier generate an electronic purchase order on the B2B platform, and then it can submit a financing application to the OL-SCF providers. After receipt of the application, the bank and the B2B platform jointly assess credit rating of the retailer (refers to the Joint Credit Rating mode, abbreviated as "JCR mode"), or the bank just asks the B2B platform to independently complete the credit rating task (refers to the Entrusted Credit Rating mode, abbreviated as "ECR mode"). If the application is approved, the bank pays for the purchase order on behalf of the retailer. After receiving the money, the supplier delivers the corresponding goods to a third-party logistics company (3PL) for supervision or just pledges the goods in its own warehouse. If the retailer repays within a specified period of time, the bank sends a command to the 3PL to release the goods. Finally, the retailer takes title of ownership of the goods and terminates the whole financing process.

This mode is designed to solve the short-term capital shortage problem of online retailers, especially for those seeking price discounts from suppliers through large-scale procurement or ordering in advance to avoid risks of price increase. Clearly, from Figure 1, cooperation between the 


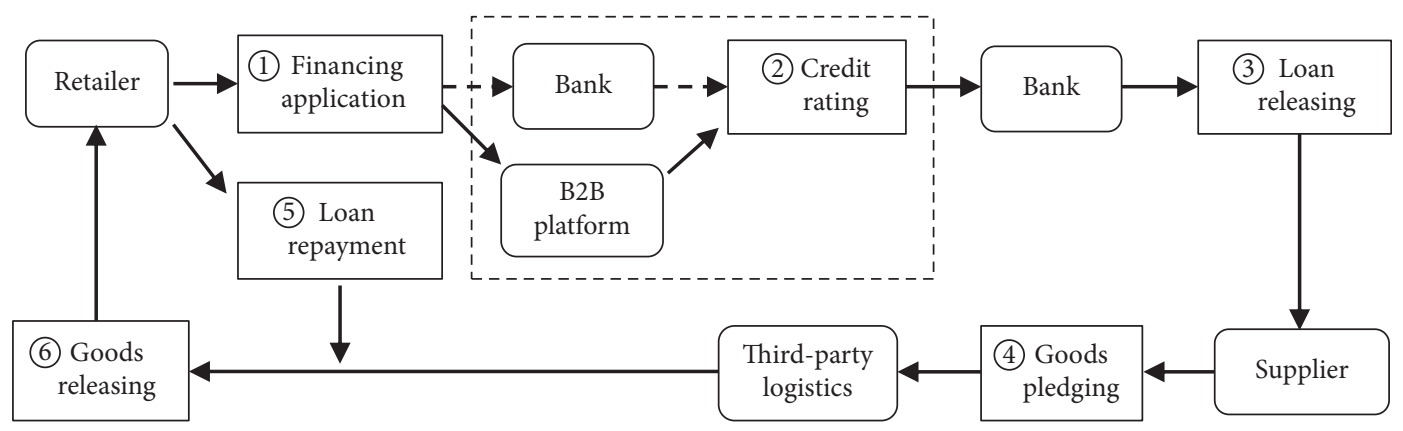

Figure 1: A simplified flowchart of online purchase order financing.

bank and the B2B platform mainly takes place at the credit rating stage. The credit rating process in the OL-SCF business has two possible modes, i.e., the JCR mode and the ECR mode. In the following, we further elaborate these two credit rating modes and clarify the principal-agent relationship between the bank and the platform in each mode.

3.1. The JCR Mode. In the traditional offline SCF business, the bank examines creditworthiness of the borrowers from various aspects, such as short-term solvency (e.g., current ratio, quick ratio, and cash flow ratio), strength of the overall supply chain (e.g., strength of upstream and downstream firms and stability of the supply chain), and characteristics of the industry in which the borrower is located (e.g., the industry development expectations and reliability of pledged goods). However, the OL-SCF further expands the credit rating indicators towards the borrower, which means that the borrower's electronic credit information generated on the B2B platform (e.g., transaction frequency, transaction amount, and customer comments) is further taken into account. Besides, the $\mathrm{B} 2 \mathrm{~B}$ platform can provide accurate information on supply chains where the borrowers are located and the logistics information among the supply chain members, which are all critical for credit rating but less accessible in the offline SCF business. Therefore, in the OLSCF business, the bank and the B2B platform usually take their respective information and technical advantages to jointly complete the credit rating work. Normally, the bank focuses on rating the financial credit (i.e., the financial indicators), while the $\mathrm{B} 2 \mathrm{~B}$ platform takes responsibility of examining the electronic credit. This is the Joint Credit Rating (JCR) mode, which comprises procedures stated in the dashed box of Figure 1.

3.2. The ECR Mode. Normally, online financing services have characteristics of "small amount, high frequency, and quick response." In some circumstances, the bank tasks the B2B platform to independently examine the borrowers for the sake of high efficiency. The electronic credit instead of the financial credit becomes the unique basis for credit assessment. This is the Entrusted Credit Rating (ECR) mode, which involves the procedures depicted by solid-line arrows in the dashed box of Figure 1. In the context of big data, abilities of $\mathrm{B} 2 \mathrm{~B}$ platforms to generate and process electronic credit information of online SMEs are greatly enhanced, and the ECR mode is likely to become the mainstream. In China, Alibaba, JYD, and other leading B2B platforms already have some fairly mature data-based credit rating technologies, and the ECR mode is being put into practice [19].

The principal-agent relationships and the hidden moral hazard problems between the bank and the B2B platform in the above two modes are quite different. For the JCR mode, the moral hazard is double since both parties may choose their own favorable effort levels in the process of determining credit rating of the borrowers, which may adversely affect the interest of the whole. However, for the ECR mode, the moral hazard is single as only the B2B platform chooses its favorable effort level, which may adversely affect the interest of the bank as well as the whole. From the perspective of moral hazard prevention, we next study the profit-sharing contract between the two parties.

\section{Design of Profit-Sharing Contract}

4.1. JCR Mode. In the JCR mode, both the bank and the platform have to put in some efforts to assess the borrowers from different aspects. Since the effort level of each side is invisible to the other, both sides are likely to choose low effort levels to optimize their respective profits but damage the interest of the whole, which results in the moral hazard problem. In this section, we design an optimal profit-sharing contract to align the interests of the two parties. The unique parameter of the contract is the profit-sharing rate (PSR) of the bank which is denoted by $g$. Referring to Figure 1 , we describe the parameters of our mathematical model as follows.

Suppose the OL-SCF service provider consists of a single bank and a single B2B platform. All funds used for the business are provided by the bank, and the credit line is $L$. The financing demand of online retailers on the platform is assumed to be far greater than $L$, and therefore, the bank and the platform need to evaluate the candidates one by one in a time sequence of borrowers' applications. Retailers who meet the rating or grading requirements can obtain the loan, and the bank terminates one round of rating when the total value of purchase orders of the approved retailers reaches $I+L$, where $I$ represents the total initial margin that the bank charges to the retailers. Then, the bank pays $I+L$ to the suppliers on behalf of the retailers. After that, the suppliers deliver goods valued $I+L$ to the $3 \mathrm{PL}$ for supervision. Define 
$c=L /(I+L)$ as the pledge rate, which is the ratio of the loan amount to the collateral value. Finally, when the loan expires, there are two possible scenarios for each retailer, i.e., either it successfully repays the loan or defaults. Assume the interest rate is $r$. In the case of successful repayment, the bank and the B2B platform share profits according to the proportion of $g: 1-g(0<g<1)$. Otherwise, in the case of loan default, the suppliers are forced to buy back the corresponding goods pledged at a discount, and the payments are collected by the bank as compensation. Let $\lambda \in[0,1]$ denote the buyback price coefficient, which is the ratio of the buyback price to the original wholesale price of the suppliers.

Let $N$ denote the number of the full indicators that OLSCF service providers use for rating borrowers, which represents the highest standard in the industry. Further, let $N_{B}$ and $N_{E}$ denote the number of indicators which should be taken into account by the bank and the B2B platform, respectively, and $N_{B}+N_{E}=N$ holds. For a pair of a specific bank and a specific platform, $\alpha_{B} \in\left[0, N_{B} / N\right]$ and $\beta_{E} \in\left[0, N_{E} / N\right]$ denote the rating effectiveness of the bank and the platform, respectively. Values of $\alpha_{B}$ and $\beta_{E}$ are affected by the technical levels of the selected bank and the platform. Let $P$ be an average probability of successful repayment of the borrowing by the approved retailers, and assume $P=\alpha_{B} S_{B}+\beta_{E} S_{E}$. Among them, $S_{B}, S_{E} \in[0,1]$ denote the effort levels of the bank and the platform, respectively, which can be set by each side but not visible to the other. In fact, $P \in[0,1]$ measures the ratio of the number of examined indicators to the full number of indicators, reflecting the stringency of the credit-rating work. Intuitively, the stricter the credit-rating work the service providers conduct towards the borrowers, the higher the probability of the borrowers' successful repayment will be.

Once the effort level is determined, the corresponding effort cost happens. In general, as the effort level increases, more complex indicators are included, implying the marginal cost of effort increases. Without loss of generality, we assume the effort cost follows a quadratic form to the effort level [32], i.e., $C_{B}=\theta_{B} S_{B}^{2} / 2$ and $C_{E}=\theta_{E} S_{E}^{2} / 2$, in which $\theta_{B}$ and $\theta_{E}$ are the effort cost coefficients. In addition, we use $1 / \theta_{B}$ and $1 / \theta_{E}$ to measure the rating efficiencies of the bank and the platform, respectively. Undoubtedly, for a given effort level, as the rating efficiency increases, the corresponding cost decreases, which is in line with common sense.

Furthermore, rating effectiveness and efficiency are collectively referred to as "rating ability" in this paper. Let $R_{B}=$ $\alpha_{B}^{2} / \theta_{B}$ and $R_{E}=\beta_{E}^{2} / \theta_{E}$ represent the rating abilities of the bank and the platform, respectively. Aside from human factors which are not under consideration, the technical level is the decisive factor for rating abilities of the bank and the B2B platform. For instance, development and application of big-data-related technologies have greatly improved the B2B platform's abilities for mining and processing the behavioral data of online-trading SMEs [19], thus actively enhancing the rating abilities (i.e., effectiveness and efficiency) of the platform. Main notations in this paper are summarized in Table 1.

Two crucial assumptions for the parameters are made as follows.
Assumption 1. $\lambda>c$, which means that the buyback price coefficient is larger than the pledge rate. This assumption is made to ensure that the bank will not bear the risk loss of the loan principal even in the case of borrowers' default. (The risk control innovation is a major feature of SCF services. For purchase order financing, the third-party goods supervision along with supplier's buyback guarantee can effectively hedge the risks faced by the bank. In practice, a buyback price coefficient satisfying $\lambda>c$ is usually forced by the bank to ensure the security of its loan principal in the case of the retailers' default. In detail, the expected amount of default loans is $L(1-P)$, and the bank's expected revenue from disposing pledges is $L \lambda(1-P) / c$, and then this assumption ensures $L \lambda(1-P) / c>L(1-P)$.)

Assumption 2. $\lambda<c(1+r g)$, which means that the buyback price coefficient is smaller than a critical value. This assumption is made to ensure that the unit capital return of the bank in the case of borrowers' default is less than that in the case of borrowers' successful repayment. (The unit capital return of the bank in the case of retailers' default is $\lambda / c$, while the number is $(1+r g)$ in the case of retailers' successful repayment. This assumption ensures $\lambda / c<1+r g$. Otherwise, if $\lambda / c \geq 1+r g$, the bank will be more willing to embrace a default situation, which undoubtedly induces a serious moral hazard problem since the bank will be reluctant to make any effort to rate the borrowers.)

In the following, we start to build the models. The time value of money is assumed to be in line with the risk-free interest rate, i.e., $r_{f}$, and both the bank and the platform are assumed to be rational, their goals being to maximize their respective utilities. For convenience, both parties are assumed to be risk neutral; thus, their utility functions can be directly expressed in terms of their respective expected profits. (In the OL-SCF business, transaction costs may be significantly lower compared to traditional loans due to concentration of customers on the platform and assistance of the platform in credit rating. In fact, the decline in transaction costs has been well reflected in the loan interest rates charged by banks for online borrowers, and generally speaking, interest rates charged by banks in the OL-SCF business are much lower than those in traditional loans to SMEs. For example, in the Chinese market, the average loan interest rate in the OL-SCF business is around 6\%, while that in traditional loans to SMEs may reach $10 \%$. Thus, this paper does not consider the transaction costs but only models the effort cost of credit rating and the time cost of funds for the bank, as shown in the last two terms in equation. (1).), i.e.,

$$
\begin{aligned}
& U_{B}=L P(1+r g)+\frac{L \lambda(1-P)}{c}-L\left(1+r_{f}\right)-\frac{\theta_{B} S_{B}^{2}}{2}, \\
& U_{E}=L P r(1-g)-\frac{\theta_{E} S_{E}^{2}}{2} .
\end{aligned}
$$

In the JCR mode, both the bank and the platform need to make some efforts for rating the borrowers, and both the efforts contribute to the probability of successful repayment by the approved borrowers. Since the effort level of each side 
TABle 1: Main notations and definitions.

\begin{tabular}{|c|c|}
\hline Notations & Definitions \\
\hline$L$ & Credit line (loan amount) \\
\hline$I$ & Total amount of initial margin the bank charges to the retailers \\
\hline$c$ & Pledge rate, and $c=L /(I+L)$ \\
\hline$r$ & Loan interest rate \\
\hline$r_{f}$ & Risk-free interest rate \\
\hline$g$ & Profit-sharing rate of the bank \\
\hline$\hat{\lambda}$ & Buyback price coefficient of the suppliers \\
\hline$P$ & Probability of the approved retailers' successful repayment \\
\hline$\alpha_{B}$ & Rating effectiveness of the bank \\
\hline$\beta_{E}$ & Rating effectiveness of the $\mathrm{B} 2 \mathrm{~B}$ platform \\
\hline$\theta_{B}$ & Effort cost coefficient of the bank, and $1 / \theta_{B}$ measures the rating efficiency of the bank \\
\hline$\theta_{E}$ & Effort cost coefficient of the $\mathrm{B} 2 \mathrm{~B}$ platform, and $1 / \theta_{E}$ measures the rating efficiency of the $\mathrm{B} 2 \mathrm{~B}$ platform \\
\hline$R_{B}$ & Rating ability of the bank, and $R_{B}=\alpha_{B}^{2} / \theta_{B}$. \\
\hline$R_{E}$ & Rating ability of the $\mathrm{B} 2 \mathrm{~B}$ platform, and $R_{E}{ }^{D}=\beta_{E}^{2} / \theta_{E}$. \\
\hline$S_{B}$ & Effort level of the bank \\
\hline$S_{E}$ & Effort level of the B2B platform \\
\hline$C_{B}$ & Effort cost of the bank \\
\hline$C_{E}$ & Effort cost of the B2B platform \\
\hline$U_{B}$ & Expected utility of the bank \\
\hline$U_{E}$ & Expected utility of the B2B platform \\
\hline
\end{tabular}

is invisible to the other, each side has an incentive to choose favorable effort level to optimize its self-utility at the expense of the other's interest. Therefore, in order to eliminate the moral hazard problem [32], we design a profit-sharing contract to align the individual interest and the joint interest. The model is shown as follows:

$$
\begin{array}{ll}
\max _{g} & \left(U_{B}+U_{E}\right) \\
\text { s.t } & S_{B}^{*}=\operatorname{argmax}_{S_{B}}\left(U_{B}\right) \\
& S_{E}^{*}=\operatorname{argmax}_{S_{E}}\left(U_{E}\right) .
\end{array}
$$

By solving equation (3), Proposition 1 can be obtained.

Proposition 1. In the JCR mode, the optimal profit-sharing rate (PSR) of the bank should be set as

$$
g^{*}=\frac{R_{B} r+R_{E}(\lambda / c-1)}{\left(R_{B}+R_{E}\right) r} .
$$

Proof. See Appendix A.

Based on Assumptions 1 and 2, it is easy to verify that $0<g^{*}<1$ is always true, which ensures the rationality of the obtained contract. Under the profit-sharing contract with $g^{*}$, the bank and B2B platform can maximize their joint interest while maximizing their own interests.

4.2. ECR Mode. In the ECR mode, the bank completely entrusts the platform to rate the borrowers. The probability of successful repayment of the approved borrowers only depends on the effort level of the platform, i.e., $P=\beta_{E} S_{E}$. Undoubtedly, the platform will always choose a favorable effort level to maximize its own profit. In order to eliminate the risk of the moral hazard problem [32], we design a profitsharing contract to align the interests of the platform and the whole. (Note that if we align the interests of the platform and the bank in the ECR mode, the problem becomes a Stackelberg game with the bank acting as the leader, i.e., the platform chooses its favorable effort level first and then the bank chooses the optimal profit-sharing rate by applying the platform's best response. Such a scenario occurs only when the bank plays an absolutely dominant role in the cooperation; however, in the ECR mode, the leadership of the bank is significantly weakened; thus, such an approach is unreasonable. Therefore, the contract aligning the interests of the platform and the whole is closer to the reality.) In the ECR mode, the B2B platform's utility function still follows equation (2), while the bank's utility function becomes

$$
U_{B}=L P(1+r g)+\frac{L \lambda(1-P)}{c}-L\left(1+r_{f}\right) .
$$

Obviously, the item of effort cost in the bank's utility function is removed. Furthermore, the optimization problem becomes

$$
\begin{aligned}
& \max _{g}\left(U_{B}+U_{E}\right) \\
& \text { s.t } S_{E}^{*}=\operatorname{argmax}_{S_{E}}\left(U_{E}\right) .
\end{aligned}
$$

By solving equation (6), we obtain the following proposition.

Proposition 2. In the ECR mode, the optimal profit-sharing rate (PSR) of the bank should be set as

$$
g^{* *}=\frac{\lambda / c-1}{r} \text {. }
$$

Proof. The proof is similar to that of Proposition 1, and thus is omitted.

Based on Assumptions 1 and 2, it is easy to verify that $0<g^{* *}<1$ is always true, which ensures the rationality of the obtained contract. Under the profit-sharing contract with 
$g^{* *}$, the B2B platform can select optimal effort level to maximize its own profit and at the same time maximizing its joint profit with the bank.

From Proposition 2, it is interesting to find that the optimal PSR of the bank in the ECR mode is not dependent on rating ability of the platform, i.e., $R_{E}$, which is different from that in the JCR mode, where the optimal PSR is influenced by the rating abilities of both the bank and the B2B platform.

In fact, different expressions of the bank's PSR in the two modes, i.e., the JCR mode and the ECR mode, reflect the leadership transfer between the bank and the platform in the OL-SCF business. In the following section, we compare the PSR of the bank in the two modes and reveal the transfer of leadership between the two parties under the big data scenario.

\section{Transfer of Leadership}

In order to compare the optimal PSR in the two modes, i.e., JCR and ECR, we first investigate some properties of the PSR in the JCR mode. The following corollary presents how the optimal PSR of the bank changes as the rating ability of the $\mathrm{B} 2 \mathrm{~B}$ platform rises.

Corollary 1. In the JCR mode, when the rating ability of the $B 2 B$ platform rises, the optimal profit-sharing rate (PSR) of the bank will monotonically decrease, i.e., $\partial g^{*} / \partial R_{E}<0$.

\section{Proof. See Appendix B.}

Corollary 1 implies that the leadership of the bank gets gradually weakened with increase of the B2B platform's rating ability (i.e., effectiveness and efficiency). In the context of big data era, rating ability of the B2B platform will be greatly enhanced as data mining and processing techniques develop further. For example, more advanced data mining technologies would help the platform get access to rating indicators which are barely accessible by traditional techniques, such as the structure and features of the supply chain networks in which the online borrowers are located, acquisition, and quantification of online customer comments, and so on. It will help the B2B platform further complete its rating indicators and thus improve its rating effectiveness. Besides, development of data processing technologies will enhance the platform's rating efficiency. So, as the information technology develops, rating ability of the $\mathrm{B} 2 \mathrm{~B}$ platform definitely increases, leading to the decrease of the PSR of the bank. This also implies that the leadership of the OL-SCF business will be gradually transferred from the bank to the platform in the big data era. In particular, if the rating ability of the B2B platform grows to infinity, the following happens.

Corollary 2. When the rating ability of the B2B platform grows to infinity, the optimal profit-sharing rate (PSR) of the bank in the JCR mode will approach to that in the ECR mode, i.e., $\lim _{R_{E} \longrightarrow+\infty} g^{*}=g^{* *}$.
Proof. See Appendix C.

Corollary 2 implies that when the rating ability of the B2B platform is extremely high, the bank stops the credit-rating work and passively accepts the ECR mode. Based on Corollaries 1 and 2, the following proposition can be obtained.

Proposition 3. The optimal profit-sharing rate (PSR) of the bank in the ECR mode is no more than that in the JCR mode, i.e., $g^{* *} \leq g^{*}$, and thus is the lowest level in the business.

\section{Proof. See Appendix D.}

As we have stated, the ECR mode will finally replace the JCR mode to be the mainstream in the big data era due to the improvement of the B2B platform's rating ability and the quick-response requirement of the borrowers. By then, the bank can only gain the lowest level of PSR in the business, and the leadership of the bank will be maximally transferred to the B2B platform. This, from a certain angle, explains why leading banks in China "divorced" B2B platforms and rushed to set up their self-operating platforms during 2011 to 2013. In fact, the absolute benefit is another key factor that influences the behavioral choice of the bank, which we analyze in Section 6.

\section{Change of Absolute Benefit}

In Section 5, we have described the transfer of leadership between the bank and the B2B platform as the platform's rating ability improves in the big data era and explained why banks in China "divorced" B2B platforms during 2011 to 2013 from the angle of leadership transfer. Usually, the behavior of a firm is complex and is affected by multiple factors. For the bank with the rational person hypothesis, the decisive factor affecting its behavior choice would be the absolute benefit. Therefore, in this section, from the perspective of absolute benefit change, we further explain the complex partnership between the bank and the B2B platform.

From equation (1), it is clear that the B2B platform's rating ability affects the bank's absolute benefit through a variety of intermediate parameters, i.e., the optimal PSR, the optimal effort levels of both sides, and the probability of repayment. Such influences are complex. For convenience, in this section, the rating effectiveness, i.e., $\beta_{E}$, is chosen as the unique variable to measure the level of rating ability of the platform. Undoubtedly, a rise in $\beta_{E}$ means a rise in $R_{E}$ with a fixed $\theta_{E}$. In the following, we first give a lemma on how the optimal effort levels of both sides change with the increase of $\beta_{E}$.

Lemma 1. In the JCR mode, as the rating ability of the $B 2 B$ platform rises, the optimal effort level of the platform increases while that of the bank decreases, i.e., $d S_{E}^{*} / d \beta_{E}>0$ and $d S_{B}^{*} / d \beta_{E}<0$.

\section{Proof. See Appendix E.}

Lemma 1 shows that, as the rating ability of the $\mathrm{B} 2 \mathrm{~B}$ platform rises, the bank will lower its level of effort on rating 
the borrowers while let the platform work harder, which can save the bank some effort costs. Further, the changes in the B2B platform's rating ability and the effort levels of both sides jointly affect the expected probability of repayment. The following lemma summarizes how such probability changes.

Lemma 2. In the JCR mode, there exists a threshold $\beta_{E}^{\prime}$ that solves

$$
\beta_{E}^{\prime}=\frac{L R_{B} R_{E}(1+r-\lambda / c)\left(R_{B}-R_{E}\right)}{S_{E}\left(R_{B}+R_{E}\right)^{2}},
$$

when $\beta_{E}<\beta_{E}^{\prime}$, we have $d P / d \beta_{E}<0$; and when $\beta_{E}>\beta_{E}^{\prime}$, we have $d P / d \beta_{E}>0$.

\section{Proof. See Appendix F.}

Lemma 2 implies that, as the B2B platform's rating ability increases, the expected probability of the borrowers' repayment first decreases and then increases. Such a finding can be further explained as follows. From Lemma 1, as $\beta_{E}$ rises, $S_{E}$ increases while $S_{B}$ decreases. When $\beta_{E}$ is relatively small, i.e., $\beta_{E}<\beta_{E}^{\prime}$, the positive contribution of the platform to successful repayment probability, i.e., $\Delta \beta_{E} S_{E}$, cannot offset the negative impact of the bank, i.e., $-\Delta \alpha_{B} S_{B}$; thus, $P$ shows a trend of decline. When $\beta_{E}$ is relatively large, i.e., $\beta_{E}>\beta_{E}^{\prime}$, the positive contribution of the platform becomes more significant, which causes $P$ to stop falling and start rising.

We further move on to explore the effect of the rise in the platform's rating ability on the absolute benefit of the bank. First, it is clear that when $\beta_{E}=0, g^{*}=1$, and $S_{E}=0$, then the bank's profit/utility $U_{B}^{0}$ can be solved as

$$
U_{B}^{0}=U_{B}\left(\beta_{E}=0\right)=\frac{L^{2} R_{B}}{2}\left(1+r-\frac{\lambda}{c}\right)^{2}+L\left(\frac{\lambda}{c}-1-r_{f}\right) \text {. }
$$

Then, we get Proposition 4.

Proposition 4. In the JCR mode, let $\widehat{\beta}_{E}$ be the larger root of $U_{B}\left(\beta_{E}\right)=U_{B}^{0}$, and $\underline{\beta}_{E}$ solves

$$
\underline{\beta_{E}}=\frac{\theta_{E} S_{E}(1+r g-\lambda / c)\left(R_{B}+R_{E}\right)^{2}}{R_{B}(1+r-\lambda / c)\left(P-\alpha_{B} S_{B} R_{E} / R_{B}\right)} .
$$

(a) When $0<\beta_{E}<\beta_{E}$, $d U_{B} / d \beta_{E}<0$ and $U_{B}<U_{B}^{0}$

(b) When $\beta_{E}<\beta_{E}<\widehat{\beta}_{E}, d U_{B} / d \beta_{E}>0$ and $U_{B}<U_{B}^{0}$

(c) When $\beta_{E}>\widehat{\beta}_{E}, d U_{B} / d \beta_{E}>0$ and $U_{B}>U_{B}^{0}$

Proof. See Appendix G.

Proposition 4 implies that when the B2B platform's rating ability is low-level, i.e., $0<\beta_{E}<\beta_{E}$, as the platform's rating ability rises, the expected utility of the bank decreases. Along with conclusions in Corollary 1, the bank suffers a "double decline" in its leadership (PSR) and absolute benefit (expected utility), which fully explain why the banks in China "divorced" Alibaba and rushed to build their selfoperating platforms during 2011 to 2013.
Then, when the platform's rating ability is medium-level, i.e., $\underline{\beta}_{E}<\beta_{E}<\widehat{\beta}_{E}$, as the platform's rating ability rises, the bank's absolute benefit begins to increase but does not return to its original level. So, most banks in this period hold a "wait-and-see" attitude.

Finally, when the platform's rating ability is high-level, i.e., $\beta_{E}>\widehat{\beta}_{E}$, as the platform's rating ability rises, the absolute benefit of the bank begins to exceed its original level. Thus, the rational banks would like to get involved again even at the expense of losing a portion of leadership, which exactly explains why the banks in China have come back to "remarry" Alibaba since 2014.

In summary, the rise in the $\mathrm{B} 2 \mathrm{~B}$ platform's rating ability is of essence for evolution of the complex partnership between the bank and the B2B platform. The rationale is analyzed as follows. From Corollary 1, even though the bank's PSR $\left(g^{*}\right)$ is strictly decreasing with the platform's rating ability $\left(\beta_{E}\right)$, as $\beta_{E}$ reaches a threshold, i.e., $\beta_{E}^{\prime}$, the probability of repayment $(P)$ begins to increase, as shown in Lemma 2. Besides, from Lemma 1 , as $\beta_{E}$ rises, the optimal effort level of the bank continues to decrease, which helps the bank save some effort costs. To sum up, when $\beta_{E}$ reaches a certain level, i.e., $\beta_{E}$, the positive impacts of the improvement of repayment probability and the saving of effort cost completely compensate for the negative impacts of the decline in the bank's PSR and finally lead to the consistent rise of the bank's absolute benefit.

\section{Numerical Example}

Assume the credit line of the bank is $L=100$, and the loan interest rate is $r=0.06$. Based on the practice of most banks in China, the pledge rate is set as $c=0.7$. The value of buyback price coefficient $\lambda$ should be chosen to satisfy Assumptions 1 and 2 . Here, we set $\lambda=0.73$. The rating effectiveness and efficiency of the bank are randomly chosen as $\alpha_{B}=0.3$ and $\theta_{B}=0.8$, and the rating efficiency of the B2B platform is randomly set as $\theta_{E}=0.9$. Following the practice in Section 6, the rating effectiveness, i.e., $\beta_{E}$, is chosen as the unique variable to measure the level of the platform's rating ability, and without the loss of generality, we assume $\beta_{E} \in[0,0.6]$, where $0.6=N_{E} / N$ represents the upper bound of the rating effectiveness of the $\mathrm{B} 2 \mathrm{~B}$ platform (refer to Section 4.1 for details on the meanings of $N_{E}$ and $N$ ).

The risk-free interest rate is set at $r_{f}=0.02$. In Table 2, under different values of $\beta_{E}$, we compute values of the optimal PSR of the bank and probability of the retailers' successful repayment, as well as the expected utilities of both the bank and the B2B platform. From the bank's perspective, the optimal PSR $\left(g^{*}\right)$ and expected utility $\left(U_{B}\right)$ are the two main indicators that affect its behavioral choice. Figure 2 visually displays the changes of these two indicators as the B2B platform's rating ability increases.

Figure 2 shows that $g^{*}$ is strictly decreasing with $\beta_{E}$, while $U_{B}$ first decreases and then increases with the increase of $\beta_{E}$ (which can be roughly depicted as a " $U$ " shape), corresponding to conclusions in Corollary 1 and Proposition 4. Further, based on Figure 2, growth of the platform's rating ability can be divided into three stages. 
TABLE 2: The values of optimal PSR and expected utilities under different $\beta_{E}$.

\begin{tabular}{cccccc}
\hline$\beta_{E}$ & $g^{*}$ & $P$ & $U_{B}$ & $U_{E}$ & $U_{B}+U_{E}$ \\
\hline 0.0 & 1.000 & 0.193 & 2.451 & 0.000 & 2.451 \\
0.1 & 0.974 & 0.177 & 2.425 & 0.027 & 2.452 \\
0.2 & 0.919 & 0.160 & 2.397 & 0.072 & 2.469 \\
0.3 & 0.866 & 0.183 & 2.405 & 0.115 & 2.520 \\
0.4 & 0.825 & 0.261 & 2.435 & 0.176 & 2.611 \\
0.5 & 0.797 & 0.395 & 2.467 & 0.275 & 2.742 \\
0.6 & 0.777 & 0.578 & 2.495 & 0.415 & 2.910 \\
\hline
\end{tabular}

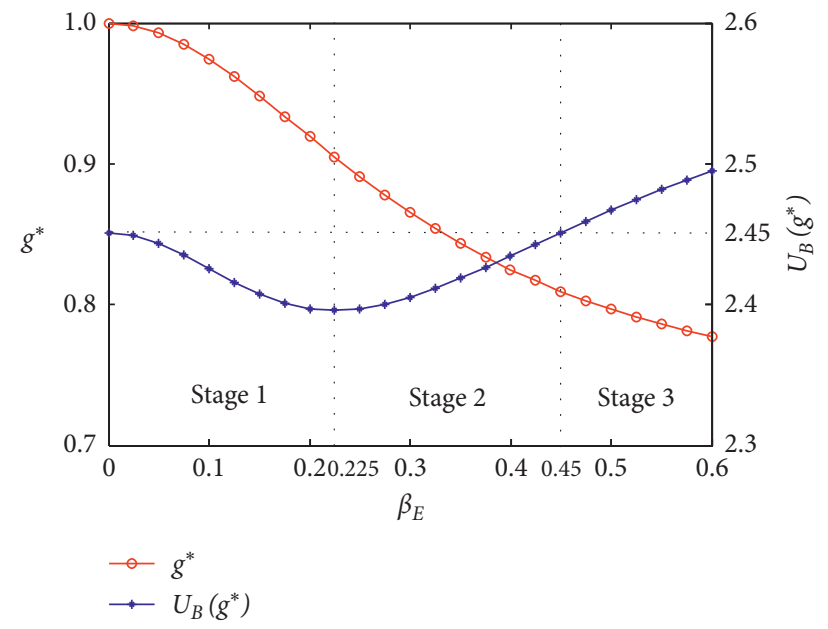

Figure 2: Changes of $g^{*}$ and $U_{B}$ as $\beta_{E}$ increases.

Stage 1: low-level rating ability, i.e., $\beta_{E} \in(0,0.225)$. In such an initial stage of growth of the $\mathrm{B} 2 \mathrm{~B}$ platform's rating ability, the bank suffers a "double decline" in its PSR and expected utility, which means that both the leadership and absolute benefit of the bank suffer and that explains why the banks in China "divorced" Alibaba and rushed up to build their self-operating platforms during 2011 to 2013. This stage corresponds to case (a) in Proposition 4.

Stage 2: medium-level rating ability, i.e., $\beta_{E} \in(0.225,0.45)$. In this stage, as the platform's rating ability grows, the bank's PSR continues to decline while its absolute benefit begins to increase. However, the absolute benefit of the bank has not returned to its original level; thus, most banks will hold a "wait-and-see" attitude. This stage corresponds to case (b) in Proposition 4.

Stage 3: high-level rating ability, i.e., $\beta_{E} \in(0.45,0.6)$. Although the changing trend of the two indicators is similar to that in Stage 2, absolute benefit of the bank begins to exceed its original level. A rational bank would like to get involved again even at the expense of losing a portion of leadership, which explains why banks in China have come back to "remarry" Alibaba since 2014. This stage corresponds to case (c) in Proposition 4.

Furthermore, the sustained increase of the bank's absolute benefit in Stages 2 and 3 can be attributed to the improvement of repayment probability and saving of the bank's effort cost, as analyzed in Section 6. Figures 3 and 4 further show the changing trends of repayment probability

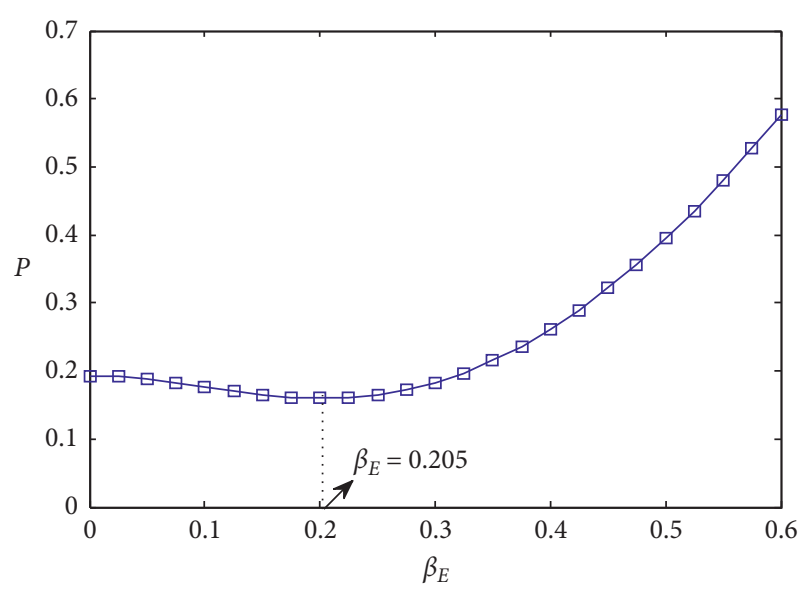

Figure 3: Changes of $P$ as $\beta_{E}$ increases.

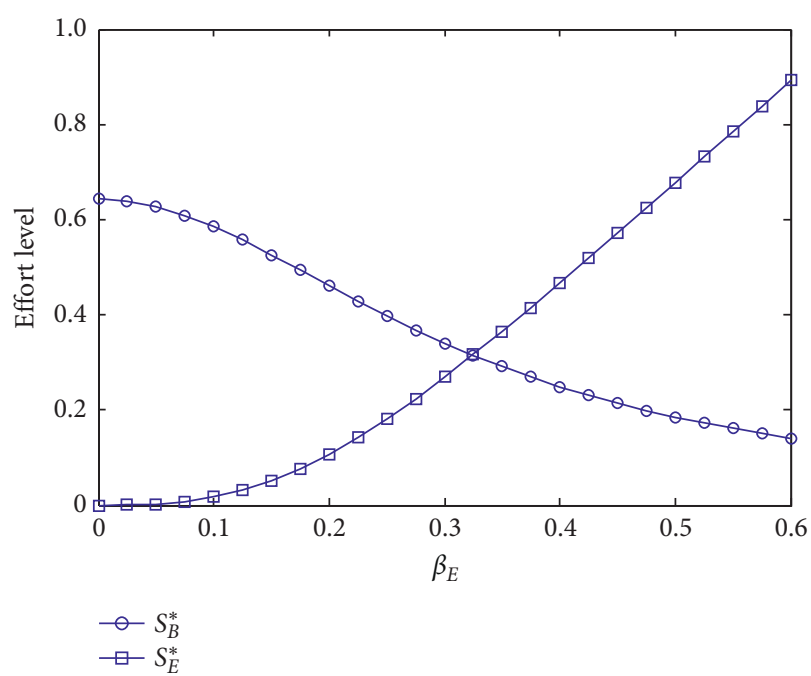

Figure 4: Changes of $S_{B}^{*}$ and $S_{E}^{*}$ as $\beta_{E}$ increases.

and both sides' effort levels with the B2B platform's rating ability, which exactly verify the conclusions in Lemmas 1 and 2 .

\section{Conclusions}

The B2B-based online supply chain finance (OL-SCF) has developed rapidly in the latest decade. From a dual perspective of leadership transfer and absolute benefit change, this paper presents a theoretical interpretation on evolution of the complex partnerships between the OL-SCF service providers (i.e., banks and $\mathrm{B} 2 \mathrm{~B}$ platforms) in the Chinese market. It is found that enhancement of B2B platforms' rating ability driven by progress of information technology is of essence for such an evolution.

First, in the OL-SCF business with a single bank and a single $\mathrm{B} 2 \mathrm{~B}$ platform, the principal-agent relationships between the two parties are analyzed under the Joint Credit Rating (JCR) mode and the Entrusted Credit Rating (ECR) mode. Then, the moral hazard models are built to investigate the optimal profit-sharing contracts between the two parties. 
It is found that the bank's optimal profit-sharing rate in the JCR mode is monotonically decreasing with the B2B platform's rating ability (i.e., effectiveness and efficiency) towards online borrowers, which implies that the leadership of the bank gets gradually weakened as the platform's rating ability grows in the context of big data era. When the platform's rating ability is extremely high, the bank can only passively accept the ECR mode and gain the lowest profitsharing rate in the cooperation. Furthermore, the absolute benefit is introduced to explain the behavioral choice of the bank. It is found that, at the initial stage of growth of the B2B platform's rating ability, the leadership and the absolute benefit of the bank suffer a "double decline," which explains why the leading banks in China "divorced" the B2B platforms during 2011 to 2013. However, when the platform grows to "maturity," the absolute benefit of the bank finally exceeds its original level, and then the rational bank begins to cooperate with the platform again even at the expense of losing a portion of its leadership, which answers why the banks in China have come back to "remarry" the B2B platforms since 2014.

Managerial implications of the above findings are manifold. First, this paper reveals the impacts of B2B platforms' rating ability driven by technical progress in the big data era on evolution of the partnerships between banks and $\mathrm{B} 2 \mathrm{~B}$ platforms in the OL-SCF business and theoretically explains the specific practice in the Chinese market, i.e., the complex "marriage-divorce-remarriage" process between the two parties. These findings can provide references for other markets around the world to develop OLSCF services. Second, in terms of the entry timing, banks should choose to cooperate with "mature" B2B platforms even if it means sacrificing a part of leadership (profitsharing rate), since the rise of borrowers' repayment probability and the saving of effort costs can bring the banks more absolute benefit. Last but not the least, the results of this study provide a blueprint for the partnership between banks and B2B platforms in the OL-SCF business, that is, when the credit rating technology of the platforms towards online borrowers develops to a certain level, both parties receive excess returns, which means bright future for the OL-SCF business.

\section{Abbreviations}

SCF: Supply chain finance

OL- Online supply chain finance

SCF:

B2B: Business to Business (one of the main e-commerce patterns)

SMEs: Small- and medium-sized enterprises

CCB: China Construction Bank

ICBC: Industrial and Commercial Bank of China

ABC: Agricultural Bank of China

JYD: Jin Yin Dao (or treasure island in related literature), one of the leading B2B platforms in China with the website http://www.315.com.cn.

OPOF: Online purchase order financing (one of the main modes of the OL-SCF)
JCR: Joint credit rating (one credit rating mode in the OL-SCF business)

ECR: Entrusted credit rating (one credit rating mode in the OL-SCF business)

PSR: $\quad$ Profit-sharing rate

3PL: Third-party logistics.

\section{Appendix}

\section{A. Proof of Proposition 1}

Firstly, $S_{B}^{*}$ and $S_{E}^{*}$ can be solved as

$$
\begin{aligned}
& S_{B}^{*}=\frac{\alpha_{B} L}{\theta_{B}}\left(r g+1-\frac{\lambda}{c}\right), \\
& S_{E}^{*}=\frac{\beta_{E} L r(1-g)}{\theta_{E}} .
\end{aligned}
$$

Substituting them into the objective function of equation (3) and taking the first and second derivatives of $\left(U_{B}+U_{E}\right)$ with respect to $g$, we have

$$
\begin{aligned}
\frac{\partial\left(U_{B}+U_{E}\right)}{\partial g}= & L^{2} r\left(\left(1+r-\frac{\lambda}{c}\right)\left(R_{B}-R_{E}\right)\right. \\
& \left.-R_{B}\left(r g+1-\frac{\lambda}{c}\right)+R_{E} r(1-g)\right), \\
\frac{\partial^{2}\left(U_{B}+U_{E}\right)}{\partial g^{2}}= & -L^{2} r^{2}\left(R_{B}+R_{E}\right) .
\end{aligned}
$$

Obviously, the second derivative is strictly negative; thus, the objective function is concave. The global maximum point of the function can be calculated by letting equation (A.3) be zero, and the result is as shown in equation (4).

\section{B. Proof of Corollary 1}

Based on equation (4), taking the first-order derivative of $g^{*}$ with respect to $R_{E}$, after some simplification, we have

$$
\frac{\partial g^{*}}{\partial R_{E}}=\frac{R_{B}((\lambda / c)-1-r)}{\left(R_{B}+R_{E}\right)^{2} r}
$$

Obviously, the denominator is positive. Based on $\lambda / c-$ $1<r g$ (Assumption 2) and $0<g<1$, we have $\lambda / c-1<r$. Thus, the numerator of equation (B.1) is negative. Therefore, we have $\partial g^{*} / \partial R_{E}<0$.

\section{Proof of Corollary 2}

Equation (4) can be rewritten as

$$
g^{*}=\frac{\left(R_{B} / R_{E}\right) r+((\lambda / c)-1)}{\left(R_{B} / R_{E}\right) r+r} .
$$

When $R_{E} \longrightarrow+\infty$, we have $R_{B} r / R_{E} \longrightarrow 0$; thus, $g^{*} \longrightarrow(\lambda / c-1) / r$. That is to say, $\lim _{R_{E}} \longrightarrow+\infty g^{*}=g^{* *}$, which completes the proof. 


\section{Proof of Proposition 3}

Approach 1: based on Corollaries 1 and 2, the conclusion in Proposition 3 can be easily drawn. This approach takes the rating ability of the $\mathrm{B} 2 \mathrm{~B}$ platform, i.e., $R_{E}$, as an intermediate parameter.

Approach 2: $g^{*}$ and $g^{* *}$ can be directly compared with their respective expressions. Proving $g^{* *} \leq g^{*}$ is equivalent to proving $\lambda / c-1 \leq r$, which can be surely supported by Assumption 2 and $0<g<1$.

\section{E. Proof of Lemma 1}

Based on equations (A.1) and (A.2), we have

$$
\begin{aligned}
\frac{\mathrm{d} S_{E}^{*}}{\mathrm{~d} \beta_{E}} & =\frac{\partial S_{E}^{*}}{\partial \beta_{E}}+\frac{\partial S_{E}^{*}}{\partial g} \frac{\mathrm{d} g}{\mathrm{~d} \beta_{E}}=\frac{\operatorname{Lr}(1-g)}{\theta_{E}}-\frac{\operatorname{Lr} \beta_{E}}{\theta_{E}} \frac{\mathrm{d} g}{\mathrm{~d} \beta_{E}} \\
\frac{\mathrm{d} S_{B}^{*}}{\mathrm{~d} \beta_{E}} & =\frac{\partial S_{B}^{*}}{\partial g} \frac{\mathrm{d} g}{\mathrm{~d} \beta_{E}}=\frac{\operatorname{Lr} \alpha_{B}}{\theta_{B}} \frac{\mathrm{d} g}{\mathrm{~d} \beta_{E}} .
\end{aligned}
$$

Based on Corollary 2, it is clear that $\mathrm{d} g / \mathrm{d} \beta_{E}<0$; thus, we have $\mathrm{d} S_{E}^{*} / \mathrm{d} \beta_{E}>0$ and $\mathrm{d} S_{B}^{*} / \mathrm{d} \beta_{E}<0$.

\section{F. Proof of Lemma 2}

Based on $P=\alpha_{B} S_{B}+\beta_{E} S_{E}$, taking the first derivative of $P$ concerning $\beta_{E}$, we have

$$
\begin{aligned}
\frac{\mathrm{d} P}{\mathrm{~d} \beta_{E}} & =\frac{\partial P}{\partial \beta_{E}}+\frac{\partial P}{\partial S_{E}} \frac{\mathrm{d} S_{E}}{\mathrm{~d} \beta_{E}}+\frac{\partial P}{\partial S_{B}} \frac{\mathrm{d} S_{B}}{\mathrm{~d} \beta_{E}} \\
& =S_{E}+\beta_{E}\left[\frac{\operatorname{Lr}(1-g)}{\theta_{E}}-\frac{\operatorname{Lr} \beta_{E}}{\theta_{E}} \frac{\mathrm{d} g}{\mathrm{~d} \beta_{E}}\right]+\alpha_{B}\left[\frac{\operatorname{Lr} \alpha_{B}}{\theta_{B}} \frac{\mathrm{d} g}{\mathrm{~d} \beta_{E}}\right] \\
& =2 S_{E}+\operatorname{Lr}\left(R_{B}-R_{E}\right) \frac{\mathrm{d} g}{\mathrm{~d} \beta_{E}}
\end{aligned}
$$

By explicitly expressing $\mathrm{d} g / \mathrm{d} \beta_{E}$, equation (F.1) can be reformulated as

$$
A=\frac{\mathrm{d} P}{\mathrm{~d} \beta_{E}}=2 S_{E}+\frac{2 L \beta_{E} R_{B}(\lambda / c-1-r)\left(R_{B}-R_{E}\right)}{\theta_{E}\left(R_{B}+R_{E}\right)^{2}} .
$$

Taking the second derivative of $P$ concerning $\beta_{E}$, we have

$$
\begin{aligned}
\frac{\mathrm{d}^{2} P}{\mathrm{~d}\left(\beta_{E}\right)^{2}} & =\frac{\partial A}{\partial \beta_{E}}+\frac{\partial A}{\partial S_{E}} \frac{\mathrm{d} S_{E}}{\mathrm{~d} \beta_{E}}+\frac{\partial A}{\partial R_{E}} \frac{\mathrm{d} R_{E}}{\mathrm{~d} \beta_{E}} \\
& =\frac{2 L R_{B}(\lambda / c-1-r)\left(R_{B}-R_{E}\right)}{\left(R_{B}+R_{E}\right)^{2} \theta_{E}}+2\left[\frac{L r(1-g)}{\theta_{E}}-\frac{\operatorname{Lr} \beta_{E}}{\theta_{E}} \frac{\mathrm{d} g}{\mathrm{~d} \beta_{E}}\right] \\
& +\frac{2 \beta_{E}}{\theta_{E}}\left[\frac{-2 L \beta_{E} R_{B}(\lambda / c-1-r)\left(R_{B}+R_{E}\right)^{2} \theta_{E}-4 L \theta_{E} \beta_{E} R_{B}(\lambda / c-1-r)\left(R_{B}^{2}-R_{E}^{2}\right)}{\left(R_{B}+R_{E}\right)^{4} \theta_{E}^{2}}\right] \\
& =\frac{2 L r(1-g)}{\theta_{E}}+\left[\frac{L r\left(R_{B}-R_{E}\right)}{\beta_{E}}-\frac{2 L r \beta_{E}}{\theta_{E}}-\frac{2 L r \beta_{E}\left(3 R_{B}-R_{E}\right)}{\left(R_{B}+R_{E}\right) \theta_{E}}\right] \frac{\mathrm{d} g}{\mathrm{~d} \beta_{E}} \\
& =\frac{1}{\beta_{E}}\left[2 S_{E}+\operatorname{Lr}\left(R_{B}-R_{E}\right) \frac{\mathrm{d} g}{\mathrm{~d} \beta_{E}}-\frac{8 L r R_{B} R_{E}}{R_{B}+R_{E}} \frac{\mathrm{d} g}{\mathrm{~d} \beta_{E}}\right] .
\end{aligned}
$$

When $\mathrm{d} P / \mathrm{d} \beta_{E}=0$, from equation (F.1), $2 S_{E}+\operatorname{Lr}\left(R_{B}-\right.$ $\left.R_{E}\right)\left(\mathrm{d} g / \mathrm{d} \beta_{E}\right)=0$, and then we have $\mathrm{d}^{2} P / \mathrm{d}\left(\beta_{E}\right)^{2}=\left(1 / \beta_{E}\right)$ $\left(-\left(8 \operatorname{Lr} R_{B} R_{E} / R_{B}+R_{E}\right)\left(\mathrm{d} g / \mathrm{d} \beta_{E}\right)\right)>0$. It implies that $P$ is convex in $\beta_{E}$ around the unique stationary point $\beta_{E}^{\prime}$ that solves $\mathrm{d} P / \mathrm{d} \beta_{E}=0$, and $\beta_{E}^{\prime}$ is thus the global minimum point, as shown in equation (8). Clearly, when $\beta_{E}<\beta_{E}^{\prime}, \mathrm{d} P / \mathrm{d} \beta_{E}<0$, while when $\beta_{E}>\beta_{E}^{\prime}, \mathrm{d} P / \mathrm{d} \beta_{E}>0$.

\section{G. Proof of Proposition 4}

Taking the first derivative of $U_{B}$ concerning $\beta_{E}$, we have

$$
\begin{aligned}
\frac{\mathrm{d} U_{B}}{\mathrm{~d} \beta_{E}}= & \frac{\partial U_{B}}{\partial P} \frac{\mathrm{d} P}{\mathrm{~d} \beta_{E}}+\frac{\partial U_{B}}{\partial g} \frac{\mathrm{d} g}{\mathrm{~d} \beta_{E}}+\frac{\partial U_{B}}{\partial S_{B}} \frac{\mathrm{d} S_{B}}{\mathrm{~d} \beta_{E}} \\
= & {\left[L(1+r g)-\frac{L \lambda}{c}\right]\left[2 S_{E}+\operatorname{Lr}\left(R_{B}-R_{E}\right) \frac{\mathrm{d} g}{\mathrm{~d} \beta_{E}}\right] } \\
& +\operatorname{LPr} \frac{\mathrm{d} g}{\mathrm{~d} \beta_{E}}-\theta_{B} S_{B}\left(\frac{\operatorname{Lr} \alpha_{B}}{\theta_{B}} \frac{\mathrm{d} g}{\mathrm{~d} \beta_{E}}\right) \\
= & 2 L S_{E}\left(1+r g-\frac{\lambda}{c}\right)+\operatorname{Lr}\left(P-\alpha_{B} S_{B} \frac{R_{E}}{R_{B}}\right) \frac{\mathrm{d} g}{\mathrm{~d} \beta_{E}} .
\end{aligned}
$$


By explicitly expressing $\mathrm{d} g / \mathrm{d} \beta_{E}$, equation (G.1) can be reformulated as

$$
B=\frac{\mathrm{d} U_{B}}{\mathrm{~d} \beta_{E}}=\frac{2 S_{E} S_{B} \theta_{B}}{\alpha_{B}}+\frac{2 L \beta_{E} R_{B}(\lambda / c-1-r)\left(P-\alpha_{B} S_{B} R_{E} / R_{B}\right)}{\theta_{E}\left(R_{B}+R_{E}\right)^{2}} .
$$

Taking the second derivative of $U_{B}$ concerning $\beta_{E}$, we have

$$
\begin{aligned}
\frac{\mathrm{d}^{2} U_{B}}{\mathrm{~d}\left(\beta_{E}\right)^{2}} & =\frac{\partial B}{\partial \beta_{E}}+\frac{\partial B}{\partial S_{E}} \frac{\mathrm{d} S_{E}}{\mathrm{~d} \beta_{E}}+\frac{\partial B}{\partial S_{B}} \frac{\mathrm{d} S_{B}}{\mathrm{~d} \beta_{E}}+\frac{\partial B}{\partial R_{E}} \frac{\mathrm{d} R_{E}}{\mathrm{~d} \beta_{E}}+\frac{\partial B}{\partial P} \frac{\mathrm{d} P}{\mathrm{~d} \beta_{E}} \\
& =\frac{L r}{\beta_{E}}\left(P-\alpha_{B} S_{B} \frac{R_{E}}{R_{B}}\right) \frac{\mathrm{d} g}{\mathrm{~d} \beta_{E}}+\frac{2 S_{B} \theta_{B}}{\alpha_{B}}\left[\frac{L r(1-g)}{\theta_{E}}-\frac{L r \beta_{E}}{\theta_{E}} \frac{\mathrm{d} g}{\mathrm{~d} \beta_{E}}\right] \\
& +\left(\frac{2 S_{E} \theta_{B}}{\alpha_{B}}-\frac{2 L \beta_{E} \alpha_{B} R_{E}(\lambda / c-1-r)}{\left(R_{B}+R_{E}\right)^{2} \theta_{E}}\right) \frac{\operatorname{Lr} \alpha_{B}}{\theta_{B}} \frac{\mathrm{d} g}{\mathrm{~d} \beta_{E}}+\left[\frac{2 L r \beta_{E}\left(\alpha_{B} S_{B} R_{E} / R_{B}-2 P-\alpha_{B} S_{B}\right)}{\left(R_{B}+R_{E}\right) \theta_{E}}\right] \frac{\mathrm{d} g}{\mathrm{~d} \beta_{E}} \\
& +\left(\frac{2 L \beta_{E} R_{B}(\lambda / c-1-r)}{\left(R_{B}+R_{E}\right)^{2} \theta_{E}}\right)\left[2 S_{E}+L r\left(R_{B}-R_{E}\right) \frac{\mathrm{d} g}{\mathrm{~d} \beta_{E}}\right] \\
& =\frac{1}{\beta_{E}}\left[2 L S_{E}\left(1+r g-\frac{\lambda}{c}\right)+L r\left(P-\alpha_{B} S_{B} \frac{R_{E}}{R_{B}}\right) \frac{\mathrm{d} g}{\mathrm{~d} \beta_{E}}+\frac{2 L^{2} r R_{B}^{2} R_{E}\left[(r-6 r g+5 \lambda / c-5) R_{B}+(4 r-6 r g+2 \lambda / c-2) R_{E}\right]}{\left(R_{B}+R_{E}\right)^{2} R_{B}} \frac{\mathrm{d} g}{\mathrm{~d} \beta_{E}}\right] .
\end{aligned}
$$

When $\mathrm{d} U_{B} / \mathrm{d} \beta_{E}=0$, from equation (G.1), $2 L S_{E}(1+$ $r g-(\lambda / c))+\operatorname{Lr}\left(P-\alpha_{B} S_{B}\left(R_{E} / R_{B}\right)\right)\left(\mathrm{d} g / \mathrm{d} \beta_{E}\right)=0$, and then we have

$$
\frac{\mathrm{d}^{2} U_{B}}{\mathrm{~d}\left(\beta_{E}\right)^{2}}=\frac{1}{\beta_{E}}\left[\frac{2 L^{2} r R_{B}^{2} R_{E}\left[(r-6 r g+5 \lambda / c-5) R_{B}+(4 r-6 r g+2 \lambda / c-2) R_{E}\right]}{\left(R_{B}+R_{E}\right)^{2} R_{B}}\right] \frac{\mathrm{d} g}{\mathrm{~d} \beta_{E}} .
$$

Let the numerator in the outer bracket be $T, \mathrm{~d} T / \mathrm{d} g<0$. When $g$ approaches its lower bound, i.e., $g \longrightarrow(\lambda / c-1) / r$, $T>0$ surely holds, while when $g$ approaches its upper bound, i.e., $g \longrightarrow 1, T<0$ surely establishes. So, there exists $\hat{g}$ that solves $T=0$, and when $(\lambda / c-1) / r<g<\hat{g}$, we have $T>0$ and $\mathrm{d}^{2} U_{B} / \mathrm{d}\left(\beta_{E}\right)^{2}<0$; when $\hat{g}<g<1$, we have $T<0$, $\mathrm{d}^{2} U_{B} / \mathrm{d}\left(\beta_{E}\right)^{2}>0$. That is to say, $U_{B}$ is either concave or convex in $\beta_{E}$ around $\beta_{E}$ that solves $\mathrm{d} U_{B} / \mathrm{d} \beta_{E}=0$. Furthermore, from equation (G.1), we have

$$
\left.\frac{\mathrm{d} U_{B}}{\mathrm{~d} \beta_{E}}\right|_{\beta_{E} \rightarrow 0}=\operatorname{LrP} \frac{\mathrm{d} g}{\mathrm{~d} \beta_{E}}<0 .
$$

It can be inferred that $U_{B}$ is convex in $\beta_{E}$ around the unique stationary point $\underline{\beta}_{E}$, and $\underline{\beta}_{E}$ is thus the global minimum point, as shown in equation (10). It also implies that when $\beta_{E}=\underline{\beta}_{E}, g\left(\underline{\beta}_{E}\right)>\hat{g}$ holds, which ensures $\mathrm{d}^{2} U_{B} / \mathrm{d}$ $\left(\beta_{E}\right)^{2}>0$.

Clearly, when $\beta_{E}<\underline{\beta}_{E}, \mathrm{~d} U_{B} / \mathrm{d} \beta_{E}<0$, while when $\beta_{E}>\underline{\beta}_{E}$, $\mathrm{d} U_{B} / \mathrm{d} \beta_{E}>0$. Suppose $\hat{\beta}_{E}\left(>\underline{\beta}_{E}\right)$ is the larger root of $U_{B}\left(\beta_{E}\right)=U_{B}^{0}$; it can be further concluded that when $0<\beta_{E}<\underline{\beta}_{E}, \mathrm{~d} U_{B} / \mathrm{d} \beta_{E}<0$ and $U_{B}<U_{B}^{0}$; when $\underline{\beta}_{E}<\beta_{E}<\widehat{\beta}_{E}$, $\mathrm{d} U_{B} / \mathrm{d} \beta_{E}>0$ and $U_{B}<U_{B}^{0}$; and when $\beta_{E}>\widehat{\beta}_{E}, \mathrm{~d} U_{B} / \mathrm{d} \beta_{E}>0$ and $U_{B}>U_{B}^{0}$.

\section{Data Availability}

No data were used to support this study.

\section{Conflicts of Interest}

The authors declare that they have no conflicts of interest. 


\section{Acknowledgments}

This work was supported by the project funded by China Postdoctoral Science Foundation (title: multi-party game and contract coordination of order-based supply chain financing systems, no. 2019M663605), the MOE (Ministry of Education in China) Project of Humanities and Social Sciences for Young Scholars (title: operational models and risk management for supply chain financing services in cross-border e-commerce under the "Belt and Road" initiative), the Fundamental Research Funds for the Central Universities, CHD (title: operational decisions of low carbon supply chain financing systems, no. 300102230626,), and the Fundamental Research Funds for the Central Universities (no. 300102238617).

\section{References}

[1] L. M. Gelsomino, R. Mangiaracina, A. Perego, and A. Tumino, "Supply chain finance: a literature review," International Journal of Physical Distribution \& Logistics Management, vol. 46, no. 4, pp. 348-366, 2016.

[2] E. Hofmann and O. Belin, Supply Chain Finance Solutions, Springer-Verlag, Berlin, Germany, 2011.

[3] J. Shi, J. Guo, S. Wang, and Z. Wang, "Credit risk evaluation of online supply chain finance based on third-party B2B e-commerce platform: an exploratory research based on China's practice," International Journal of U-and E-Service, Science and Technology, vol. 8, no. 5, pp. 93-104, 2015.

[4] A. Z. Zeng and B. K. Pathak, "Achieving information integration in supply chain management through B2B e-hubs: concepts and analyses," Industrial Management \& Data Systems, vol. 103, no. 9, pp. 657-665, 2003.

[5] P. Xie, C. Zou, and H. Liu, "The fundamentals of internet finance and its policy implications in China," China Economic Journal, vol. 9, no. 3, pp. 240-252, 2016.

[6] J. Zhao, S. Wang, and W. V. Huang, "A study of B2B e-market in China: E-commerce process perspective," Information \& Management, vol. 45, no. 4, pp. 242-248, 2008.

[7] M. L. Gomm, "Supply chain finance: applying finance theory to supply chain management to enhance finance in supply chains," International Journal of Logistics: Research and Applications, vol. 13, no. 2, pp. 133-142, 2010.

[8] H. C. Pfohl and M. Gomm, "Supply chain finance: optimizing financial flows in supply chains," Logistics Research, vol. 1, no. 3-4, pp. 149-161, 2009.

[9] D. A. Wuttke, C. Blome, and M. Henke, "Focusing the financial flow of supply chains: an empirical investigation of financial supply chain management," International Journal of Production Economics, vol. 145, no. 2, pp. 773-789, 2013.

[10] D. A. Wuttke, C. Blome, K. Foerstl, and M. Henke, "Managing the innovation adoption of supply chain finance-empirical evidence from six European case studies," Journal of Business Logistics, vol. 34, no. 2, pp. 148-166, 2013.

[11] X. Liu, L. Zhou, and Y. C. J. Wu, "Supply chain finance in China: business innovation and theory development," Sustainability, vol. 7, no. 11, pp. 14689-14709, 2015.

[12] Y. Zhu, C. Xie, B. Sun, G. J. Wang, and X. G. Yan, "Predicting China's SME credit risk in supply chain financing by logistic regression, artificial neural network and hybrid models," Sustainability, vol. 8, no. 5, pp. 433-449, 2016.

[13] D. More and P. Basu, "Challenges of supply chain finance: a detailed study and a hierarchical model based on the experiences of an Indian firm," Business Process Management Journal, vol. 19, no. 4, pp. 624-647, 2013.

[14] L. Klapper, "The role of factoring for financing small and medium enterprises," Journal of Banking \& Finance, vol. 30, no. 11, pp. 3111-3130, 2006.

[15] U. Ahmed, T. Beck, C. McDaniel, and S. Schropp, "Filling the gap: how technology enables access to finance for small- and medium-sized enterprises," Innovations: Technology, Governance, Globalization, vol. 10, no. 3, pp. 35-48, 2015.

[16] D. A. Wuttke, C. Blome, H. S. Heese, and M. ProtopappaSieke, "Supply chain finance: optimal introduction and adoption decisions," International Journal of Production Economics, vol. 178, pp. 72-81, 2016.

[17] J. Shi, R. Y. K. Fung, and J. Guo, "Optimal ordering and pricing policies for seasonal products: impacts of demand uncertainty and capital constraint," Discrete Dynamics in Nature and Society, vol. 2016, p. 13, 2016.

[18] J. Shi, J. Guo, and R. Y. K. Fung, "Decision support system for purchasing management of seasonal products: a capitalconstrained retailer perspective," Expert Systems with Applications, vol. 80, no. 1, pp. 171-182, 2017.

[19] Z. Lin, A. B. Whinston, and S. Fan, "Harnessing internet finance with innovative cyber credit management," Financial Innovation, vol. 2015, p. 24, 2015.

[20] X. Hou, Z. Gao, and Q. Wang, "Internet finance development and banking market discipline: evidence from China," Journal of Financial Stability, vol. 22, pp. 88-100, 2016.

[21] S. Oh and W. S. Kim, "Growth opportunities and trade credit: evidence from Chinese listed firms," Applied Economics, vol. 48, no. 56, pp. 5437-5447, 2016.

[22] H. Fang, J. She, and Y. Xu, "The effect of non-financial factors on credit level: an empirical study of supply chain finance based on e-commerce platform," in Proceedings of the International Conference on Engineering Management, Engineering Education and Information Technology, pp. 24-25, London, UK, 2015.

[23] P. A. Pavlou and A. Dimoka, “The nature and role of feedback text comments in online marketplaces: implications for trust building, price premiums, and seller differentiation," Information Systems Research, vol. 17, no. 4, pp. 392-414, 2006.

[24] R. Safi and Z. Lin, "Using non-financial data to assess the creditworthiness of businesses in online trade," in Proceedings of the Pacific Asia Conference on Information Systems, pp. 24-28, Chengdu, China, June 2014.

[25] W. Zhao and S. Ye, "Research on credit risk management mechanism of B2B online financing mode," in Proceedings of the 4th International Conference on Logistics, Informatics and Service Science, pp. 23-26, Berkeley, CA, USA, 2014.

[26] N. Kshetri, "Big data's role in expanding access to financial services in China," International Journal of Information Management, vol. 36, no. 3, pp. 297-308, 2016.

[27] I. Yaqoob, I. A. T. Hashem, A. Gani et al., "Big data: from beginning to future," International Journal of Information Management, vol. 36, no. 6, pp. 1231-1247, 2016.

[28] H. Wang, Z. Xu, H. Fujita, and S. Liu, "Towards felicitous decision making: an overview on challenges and trends of big data," Information Sciences, vol. 367-368, pp. 747-765, 2016.

[29] V. Kayser and K. Blind, "Extending the knowledge base of foresight: the contribution of text mining," Technological Forecasting and Social Change, vol. 116, pp. 208-215, 2016.

[30] S. Zhang, W. Xiong, W. Ni, and X. Li, "Value of big data to finance: observations on an internet credit service company in China," Financial Innovation, vol. 2015, p. 17, 2015. 
[31] J. Shi, J. Guo, and W. Yan, "Study on the incentive contract between banks and B2B platforms based on the online supply chain finance," Journal of Management Science, vol. 28, no. 5, pp. 79-92, 2015, in Chinese.

[32] T. Hellmann, "IPOs, acquisitions, and the use of convertible securities in venture capital," Journal of Financial Economics, vol. 81, no. 3, pp. 649-679, 2006. 